\title{
Simulation of Salinity Intrusion in Chao Phraya River by a Developed Mathematical Model and MacCormack Scheme with Cubic Spline Interpolation
}

\author{
Khemisara Kulmart ${ }^{1}$, Nopparat Pochai ${ }^{1,2, *}$ \\ ${ }^{1}$ Department of Mathematics, King Mongkut's Institute of Technology Ladkrabang, Thailand \\ ${ }^{2}$ Centre of Excellence in Mathematics, Thailand
}

Received October 9, 2019; Revised November 6, 2019; Accepted November 20, 2019

Copyright $\bigcirc 2019$ by authors, all rights reserved. Authors agree that this article remains permanently open access under the terms of the Creative Commons Attribution License 4.0 International License

\begin{abstract}
The purpose of this research was to develop a mathematical model for controlling salinity intrusion in Chao Phraya River, Thailand, using one-dimensional advection-diffusion equation. There have been many research studies that applied a mathematical model called dispersion model to estimating salinity concentration. Our proposed dispersion model is simple, using very few parameters, but can simulate salinity intrusion adequately. We used MacCormack scheme to approximate salinity intrusion and cubic spline interpolation technique to approximate field data including initial salinity concentrations and the concentrations at the left boundary. The MacCormack scheme and Cubic Spline interpolation technique were quite suitable for approximating real data, and the proposed mathematical model was able to predict salinity intrusion adequately.
\end{abstract}

Keywords Salinity Intrusion, MacCormack Scheme, Cubic Spline Interpolation, Chao Phraya River

\section{Introduction}

Rivers and canals are vital to the existence and livelihood of people. Chao Phraya River originated from the confluence of the Nan and Ping rivers in Nakhon
Sawan Province, Thailand. The river flows southwards for about 370 kilometers through the central plains of the country to Bangkok and then down to the sea at the Gulf of Thailand.

Chao Phraya River is maintained by the Water Transmission and Maintenance Project. A main objective of the project is to fix problems related to drought and salinity intrusion. Chao Phraya Dam releases fresh water down into the river to counter salinity intrusion from the sea [1].

In addition to the lack of fresh water during the dry season, the rise and fall of tides around an estuary is another factor that causes salinity intrusion in the Chao Phraya River. The higher level the tides are, the more salt water is pushed upwards a river. Therefore, the Thai government set a measure to constantly monitor the quality of water sources. The real-time water quality monitoring system is generally updated on an hourly basis (see Figure 1) [2] .

Ten stations along Chao Phraya river monitor the salinity concentration in real-time. If the salinity concentration exceeds the standard, the station will issue a warning to related agencies so that counter measures can be made and implemented (See Figure 2) [3] .

A mathematical model is an inexpensive tool that can help approximate, predict, and manage salinity intrusion related problems. Several researchers have conducted studies related to this issue. 


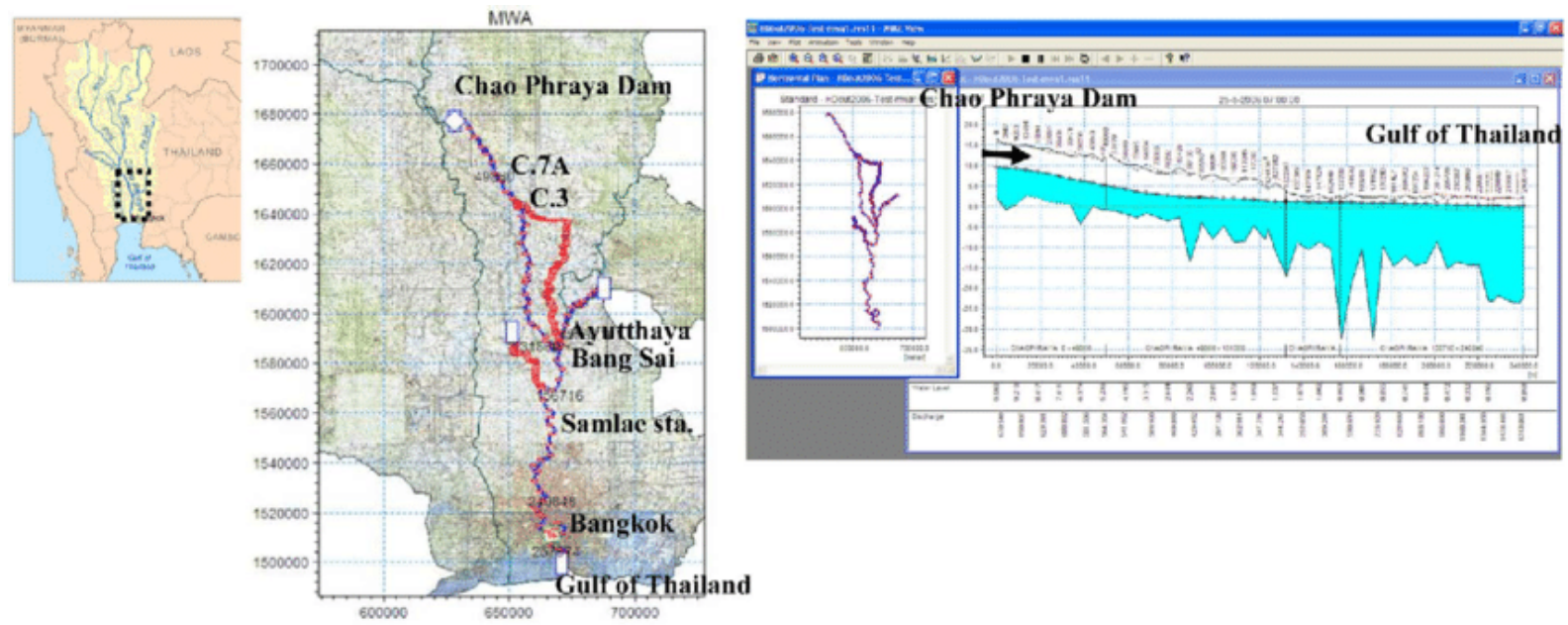

Figure 1. Study areas of the Lower Chao River and model setup [2]

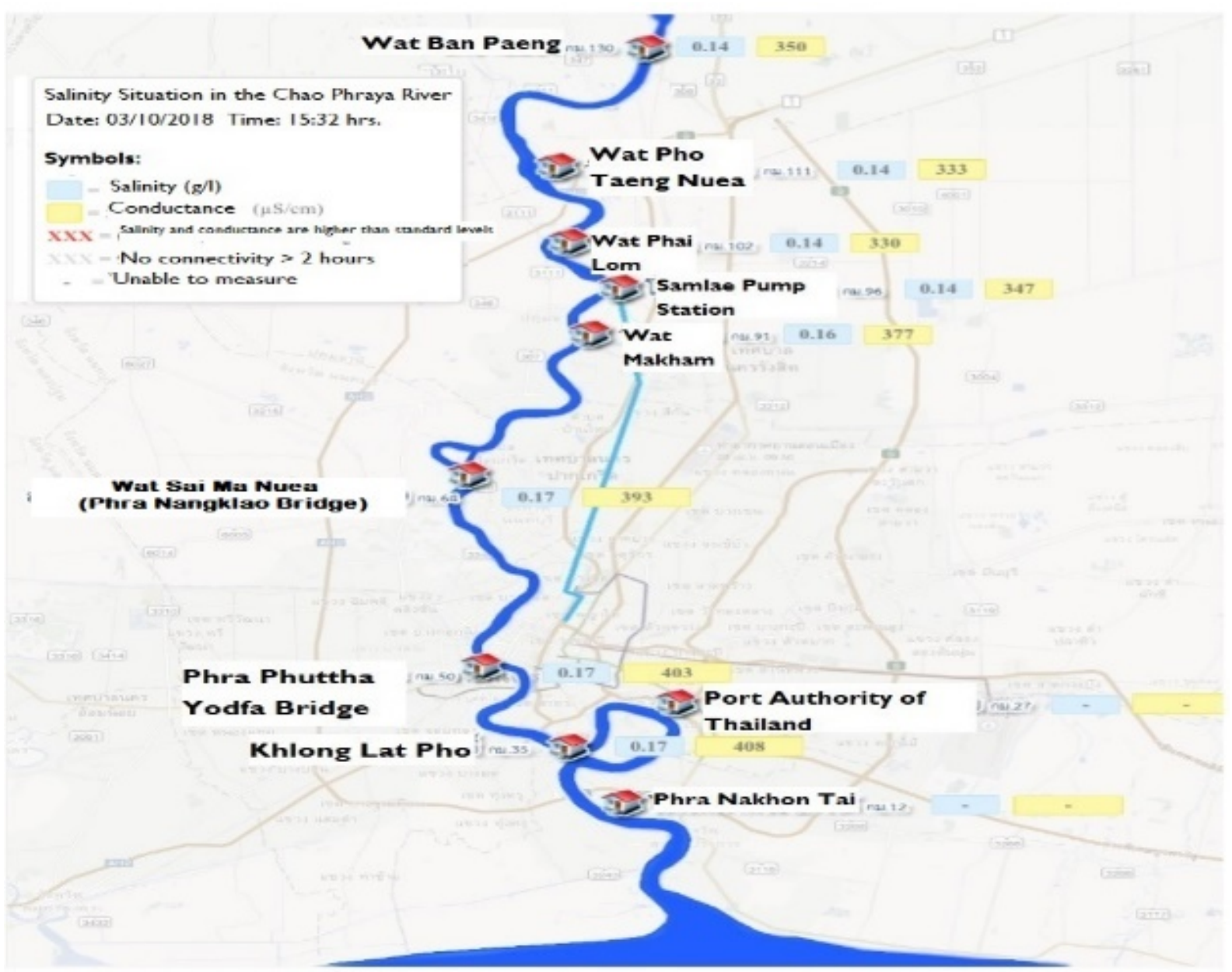

Figure 2. Real-time map of the monitoring stations focused in this study [3]

In [4], two mathematical models-Crank-Nicolson hydrodynamic model and a dispersion model with backward time central space scheme-were used to simulate pollution caused by sewage effluent in the nonuniform water flow in a stream with inconsistency in current velocity. That study demonstrates that the models were applicable to real-world cases. In [5], a better version of a finite difference scheme was used to solve advection-dispersion-reaction equation (ADRE). In that study, a hydrodynamic model and an advection-dispersion-reaction model were used to simulate pollution from sewage effluent. In [6] and [7], research has been presented on the increase of salt water.

In [8], a one-dimensional simulation of water quality 
measurement in a stream was done by using a finite volume method to come up with estimated solutions for pollutant concentration equation. The solutions provide logical and rational results that can be applied to water quality measurements. In [9], an Optimal Homotopy Asymptotic Method or OHAM was used to investigate and simulate dispersion of pollutants in water.

$\operatorname{In}[10]$, the authors focused on salinity intrusion in the area of the Tha Chin estuary, Thailand and showed that their model was suitable for forecasting natural phenomena related to salinity intrusion. In [11], the researchers came up with a numerical model of salinity's advective transport in the coastal areas, associated with artificial diffusion using upstream differences. This model could be used with small grids of two to four kilometers in the case of tidal problems, while larger grids could be applied to non-tidal problems. In , a tidally and cross-sectionally averaged model were used with Hansen and Rattray equations to simulate the distribution of salinity as well as the vertical exchange flow along the estuary of the Hudson River. Solutions from the model were assessed for the northern San Francisco Bay and the Hudson River over forcing conditions' range.

Some researchers have used Cubic Spline interpolation technique to approximate data related to salinity intrusion and salinity value. In [13], a connection between cubic splines and a popular compact finite difference formula was detailed. The researcher claimed that the compact approach for nonuniform meshes provide some advantages while the one for uniform meshes provide an additional way that helps treating edge effects. In [14], two types of cubic spline functions-cubic spline interpolation with $C^{2}$ continuity and Piecewise Cubic Hermite Spline (PCHIP) with $C^{1}$ continuity - were used for interpolation. In [15], stream water quality modeling was done by a simple modification of MacCormack and Saulyev schemes. They were used to solve dynamic one-dimensional advectiondispersion-reaction equations (ADRE). The results showed a better prediction accuracy without major loss of efficiency in computation. In [16] , the general form of teeth method was compared with a cubic spline method applied to a mathematical model of teeth of a child in order to obtain a minimum error in showing the form of general teeth while creating a better view of the nature of orthodontic wires. The results of this cubic spline method showed a symmetrical teeth's shape of curve of a normally asymmetrical curve. An example was provided in that study to show how efficient, accurate, and simple the proposed method is.

In this study, we focused on parameter optimization of a mathematical model of Chao Phraya River under the influence of tides that affected salinity values in the river. The salinity concentration generated by the model, MacCormack technique and spline interpolation were compared with real salinity concentration to see whether the model could estimate real data adequately or not.

\section{One-dimensional Salinity Intrusion Measurement Model in a River with a Diversion Dam}

\subsection{The Governing Equation}

The mathematical model describing transportation and diffusion processes is a one-dimensional advection-diffusion-reaction equation (ADRE).The advection-diffusion equation is $[5,10,17$ and 18$]$

$$
\begin{gathered}
\frac{\partial S}{\partial t}+U \frac{\partial S}{\partial x}=D \frac{\partial^{2} S}{\partial x^{2}}, \text { for all } 0 \leq x \leq L \text { and } \\
0 \leq t \leq T
\end{gathered}
$$

where $S(x, t)$ is the salinity concentration $(\mathrm{g} / \mathrm{l}) ; U$ is the water flow velocity in $x$-directions $(\mathrm{m} / \mathrm{s}) ; D$ is the salinity diffusion coefficient $\left(\mathrm{m}^{2} / \mathrm{s}\right) ; L$ is the length of a condimental stream; and $T$ is the stationary time of simulation.

Letting that

$$
U=u_{s}-k u_{w},
$$

where $u_{s}$ is the salinity advection rate; $u_{w}$ is the fresh water flow velocity function that is released by the diversion dam; and $k$ is the dilution rate of salinity by fresh water, for all $0<x \leq L$ and $0 \leq t \leq T$.

Substituting Eq. (2) into Eq. (1), we get

$$
\frac{\partial S}{\partial t}+\left(u_{s}-k u_{w}\right) \frac{\partial S}{\partial x}=D \frac{\partial^{2} S}{\partial x^{2}}
$$

\subsection{Initial and Boundary Conditions}

The effects of salinity intrusion in this estuarine, which likely will become more severe in the future, are caused by ocean tides. The mathematical model was applied to analyze the salinity intrusion. The initial salinity values were different depending on the time and distance along the river.

\subsubsection{The Initial Condition}

The initial condition was assumed to be

$$
S(x, 0)=f(x), \text { for all } 0 \leq x \leq L,
$$

where $f(x)$ is a given initial measurement of salinity concentration function along the considered river.

\subsubsection{The Boundary Condition}

The left boundary condition was assumed to be

$$
S(0, t)=g(t) \text {, for all } 0<t \leq T,
$$

where $g(t)$ is a given present measurement of salinity 
concentration function at the first monitoring station which is the closest to the estuary. The right boundary condition was assumed to be

$$
\frac{\partial S}{\partial x}(L, t)=k_{0}, \quad \text { for all } 0<t \leq T
$$

where $k_{0}$ is the rate of change of salinity concentration around the most distant monitoring station.

\section{Numerical Techniques}

The salinity concentration was calculated by using MacCormack Scheme, and the values at the left boundary condition and initial values were calculated by using Cubic spline interpolation, as described below.

\subsection{MacCormack Scheme}

We can approximate $S\left(x_{i}, t_{n}\right)$ by $S_{i}^{n}$, the value of the approximation of $S(x, t)$ at any point $x=i \Delta x$ and $t=n \Delta t$, where $0 \leq i \leq n$ and $0 \leq n \leq N$. The grid point $\left(x_{n}, t_{n}\right)$ is defined by $x_{i}=i \Delta x$ for all $i=0,1,2, \ldots, M$ and $t_{n}=n \Delta t$ for all $n=0,1,2, \ldots, N$ in which $M$ and $N$ are positive integers.

\subsubsection{The First Step of the MacCormack Scheme}

The first step of the MacCormack scheme is to approximate $S$ and its derivatives in equation (3) by forward time and forward space scheme (FTFS) as follows:

$$
\begin{aligned}
& S \cong S_{i}^{n}, \\
& \frac{\partial S}{\partial t} \cong \frac{S_{i}^{n+1}-S_{i}^{n}}{\Delta t} \\
& \frac{\partial S}{\partial x} \cong \frac{S_{i+1}^{n}-S_{i}^{n}}{\Delta x} \\
& \frac{\partial^{2} S}{\partial x^{2}} \cong \frac{S_{i+1}^{n}-2 S_{i}^{n}+S_{i-1}^{n}}{(\Delta x)^{2}} .
\end{aligned}
$$

Substituting (7) into (3), we get

$$
\left[\frac{S_{i}^{n+1}-S_{i}^{n}}{\Delta t}\right]+U\left[\frac{S_{i+1}^{n}-S_{i}^{n}}{\Delta x}\right]=D\left[\frac{S_{i+1}^{n}-2 S_{i}^{n}+S_{i-1}^{n}}{(\Delta x)^{2}}\right]
$$

for $1 \leq i \leq M$ and $0 \leq n \leq N-1$, and simplify form (8) by

$$
\left[\frac{S_{i}^{n+1}-S_{i}^{n}}{\Delta t}\right]=-\frac{U}{\Delta x}\left[S_{i+1}^{n}-S_{i}^{n}\right]=\frac{D}{(\Delta x)^{2}}\left(S_{i+1}^{n}-2 S_{i}^{n}+S_{i-1}^{n}\right) .
$$

Define $\left(C_{i}\right)_{1}$ by LHS of (9), we have

$$
\left(C_{i}\right)_{1}=-\frac{U}{\Delta x}\left(S_{i+1}^{n}-S_{i}^{n}\right)+\frac{D}{\Delta x^{2}}\left(S_{i+1}^{n}-2 S_{i}^{n}+S_{i-1}^{n}\right)
$$

and

$$
\left(C_{i}\right)_{1}=-\frac{U}{\Delta x} S_{i+1}^{n}-\frac{U}{\Delta x} S_{i}^{n}+\frac{D}{\Delta x^{2}} S_{i+1}^{n}-\frac{2 D}{\Delta x^{2}} S_{i}^{n}+\frac{D}{\Delta x^{2}} S_{i-1}^{n} .
$$

Let $A_{1}=-\frac{U}{\Delta x}+\frac{D}{(\partial x)^{2}}, A_{2}=\frac{U}{\Delta x}-\frac{2 D}{(\partial x)^{2}}, A_{3}=\frac{D}{(\partial x)^{2}}$.

We

obtain $A_{1}=-\frac{U}{\Delta x}+\frac{D}{(\partial x)^{2}}, A_{2}=\frac{U}{\Delta x}-\frac{2 D}{(\partial x)^{2}}, A_{3}=\frac{D}{(\partial x)^{2}}$, we have

$$
\left(C_{1}\right)_{i}=A_{1} S_{i+1}^{n}+A_{2} S_{i}^{n}+A_{3} S_{i-1}^{n} \text {. }
$$

For left boundary, where $i=1$, we obtain

$$
\begin{aligned}
\left(C_{1}\right) & =A_{1} S_{2}^{n}+A_{2} S_{1}^{n}+A_{3} S_{0}^{n} \\
& =A_{1} S_{2}^{n}+A_{2} S_{1}^{n}+A_{3} S_{0} .
\end{aligned}
$$

For right boundary, where $i=M$, substitute the approximate unknown value the right boundary by forward difference approximation to $\frac{\partial S}{\partial x}=0$. Let $S_{M}=S_{M-1}$, we have

$$
\begin{gathered}
\left(C_{M}\right)_{1}=A_{1} S_{M}^{n}+A_{2} S_{M+1}^{n}+A_{3} S_{M-2}^{n} \\
=\left(A_{1}+A_{2}\right) S_{M-1}^{n}+A_{3} S_{M-2}^{n}
\end{gathered}
$$

we obtain the MacCormack predictor step formulation

$$
S_{i}^{n+1}=S_{i}^{n}+\left(C_{i}\right)_{1} \Delta t
$$

\subsubsection{The Second Step of the MacCormack Scheme}

The second step of the MacCormack scheme is approximation equation (3) by a backward time and backward space scheme (BTBS) following by:

$$
\begin{aligned}
& \frac{\partial S}{\partial t} \cong \frac{S_{i}^{n+1}-S_{i}^{n}}{\Delta t} \\
& \frac{\partial S}{\partial x} \cong \frac{S_{i}^{n+1}-S_{i-1}^{n+1}}{\Delta x} \\
& \frac{\partial^{2} S}{\partial x^{2}} \cong \frac{S_{i+1}^{n+1}-2 S_{i}^{n+1}+S_{i-1}^{n+1}}{(\Delta x)^{2}} .
\end{aligned}
$$

Substituting (17) into, we get

$\frac{S_{i}^{n+1}-S_{i}^{n}}{\Delta t}+U\left[\frac{S_{i}^{n+1}-S_{i-1}^{n+1}}{\Delta x}\right]=D\left[\frac{S_{i+1}^{n+1}-2 S_{i}^{n+1}+S_{i-1}^{n+1}}{(\Delta x)^{2}}\right]$,

and simplify (18) by

$$
\frac{S_{i}^{n+1}-S_{i}^{n}}{\Delta t}=-U\left[\frac{S_{i}^{n+1}-S_{i-1}^{n+1}}{\Delta x}\right]+D\left[\frac{S_{i+1}^{n+1}-2 S_{i}^{n+1}+S_{i-1}^{n+1}}{(\Delta x)^{2}}\right] .
$$

Define $\left(C_{i}\right)_{2}$ by LHS of (3.13), we have 


$$
\begin{gathered}
\left(C_{i}\right)_{2}=-\frac{U}{\Delta x}\left(S_{i}^{n+1}-S_{i-1}^{n+1}\right)+\frac{D}{(\Delta x)^{2}}\left(S_{i+1}^{n+1}-2 S_{i}^{n+1}+S_{i-1}^{n+1}\right) \\
=\frac{D}{(\Delta x)^{2}} S_{i+1}^{n+1}+\left(-\frac{U}{\Delta x}-\frac{2 D}{(\Delta x)^{2}}\right) S_{i}^{n+1}+\left(\frac{U}{\Delta x}+\frac{D}{(\Delta x)^{2}}\right) S_{i-1}^{n+1} .
\end{gathered}
$$

Let

$B_{1}=\frac{D}{(\Delta x)^{2}}, B_{2}=-\frac{U}{\Delta x}-\frac{2 D}{(\Delta x)^{2}}, B_{3}=\frac{U}{\Delta x}+\frac{D}{(\Delta x)^{2}}$,

we have

$$
\left(C_{i}\right)_{2}=B_{1} S_{2}^{n+1}+B_{2} S_{1}^{n+1}+B_{3} S_{0}^{n+1} .
$$

For left boundary, where $i=1$

$$
\begin{aligned}
\left(C_{1}\right)_{2} & =B_{1} S_{2}^{n+1}+B_{2} S_{1}^{n+1}+B_{3} S_{0}^{n+1} \\
& =B_{1} S_{2}^{n+1}+B_{2} S_{1}^{n+1}+B_{3} S_{0} .
\end{aligned}
$$

For right boundary, where $i=M$ and approximate unknown value at right boundary by backward difference approximation to $\frac{\partial S}{\partial x}=0$. Let $S_{M+1}=S_{M}$, we have

$$
\left(C_{M}\right)_{2}=\left(B_{1}+B_{2}\right) S_{M}^{n+1}+B_{3} S_{M-1}^{n+1} .
$$

From first and second step for the MacCormack scheme takes following form:

$$
S_{i}^{M+1}=S_{i}^{n}+\frac{\Delta t}{2}\left(\left(C_{i}\right)_{1}+\left(C_{i}\right)_{2}\right) .
$$

With conditionally stable for this scheme by

$$
\text { condition } \frac{D \Delta t}{(\Delta x)^{2}}<0.5 \text {, }
$$

and

$$
\frac{U \Delta t}{(\Delta x)}<0.9
$$

\subsection{Interpolation Technique for the Initial and Boundary Condition Interpolation}

\subsubsection{Cubic Spline Interpolation}

Raw salinity concentration data were obtained by field measurement at the first monitoring station which is the closest to the Chao Phraya estuary. Function $f(x)$ and $g(t)$ were defined by using those data. In this research, cubic spline interpolation was introduced to represent the field data for initial and boundary conditions as described below.

The cubic spline interpolation method, which is a piecewise polynomial approximation, considers a unique cubic equation of each subinterval such that they have necessary conditions as first and second derivatives of a continuous cubic spline $[19,20]$.
Suppose $\left(x_{0}, y_{0}\right),\left(x_{1}, y_{1}\right),\left(x_{2}, y_{2}\right), \ldots,\left(x_{n}, y_{n}\right)$ are nodes. In all, there are $n+1$ pairs of nodes where $a=x_{0}<x_{1}<\ldots<x_{n}=b . \quad$ Function $\quad S(x) \quad$ is approximated to be between a pair of nodes. It is called a cubic spline if there exist $n$ cubic polynomials that satisfy these conditions:

(1). $S(x)$ is a cubic polynomial on each subinterval $\left[x_{i}, x_{i+1}\right]$ where $i=0,1, \ldots, n-1$

$S_{i}(x)=a_{i}+b_{i}\left(x-x_{i}\right)+c_{i}\left(x-x_{i}\right)^{2}+d_{i}\left(x-x_{i}\right)^{3}$,

$a_{i}, b_{i}, c_{i}$, and $d_{i}$ are unknown constant coefficients of each cubic polynomial,

(2). $S_{i+1}\left(x_{i+1}\right)=S_{i}\left(x_{i+1}\right)$ where $i=0,1, \ldots, n-2$,

(3). $S_{i+1}^{\prime}\left(x_{i+1}\right)=S_{i}^{\prime}\left(x_{i+1}\right)$ where $i=0,1, \ldots, n-2$,

(4). $S_{i+1}^{\prime \prime}\left(x_{i+1}\right)=S_{i}^{\prime \prime}\left(x_{i+1}\right)$ where $i=0,1, \ldots, n-2$,

(5). One of sets of boundary conditions is satisfied according to this condition as

(i). $S^{\prime \prime}\left(x_{0}\right)=S^{\prime \prime}\left(x_{n}\right)=0$ (natural boundary),

(ii). $S^{\prime}\left(x_{0}\right)=y_{0}^{\prime}$ and $S^{\prime}\left(x_{n}\right)=y_{n}^{\prime}$ (clamped boundary).

For the natural boundary conditions, there are $n$ linear equations for coefficients $c_{0}, c_{1}, c_{2}, \ldots, c_{n}$ so we can solve the solution of $c_{i}$ from a tridiagonal linear system $\boldsymbol{T} \mathbf{x}=\mathbf{b}$, where $\boldsymbol{T}$ is a tridiagonal matrix of $n \times n$ as follows

$$
\boldsymbol{T}=\left[\begin{array}{cccccc}
1 & 0 & 0 & 0 & 0 & 0 \\
h_{0} & 2\left(h_{0}+h_{1}\right) & h_{1} & \ddots & \ddots & 0 \\
0 & h_{1} & 2\left(h_{1}+h_{2}\right)_{2} & h_{2} & \ddots & 0 \\
0 & \ddots & \ddots & \ddots & \ddots & 0 \\
0 & \ddots & \ddots & h_{n-2} & 2\left(h_{n-2}+h_{n-1}\right) & h_{n-1} \\
0 & 0 & 0 & 0 & 0 & 1
\end{array}\right],
$$

$$
\mathrm{b}=\left[\begin{array}{c}
\alpha_{0} \\
\alpha_{1} \\
\vdots \\
\alpha_{n-1} \\
\alpha_{n}
\end{array}\right]=\left[\begin{array}{c}
0 \\
\frac{3}{h_{1}}\left(a_{2}-a_{1}\right)-\frac{3}{h_{0}}\left(a_{1}-a_{0}\right) \\
\vdots \\
\frac{3}{h_{n-1}}\left(a_{n}-a_{n-1}\right)-\frac{3}{h_{n-2}}\left(a_{n-1}-a_{n-2}\right) \\
0
\end{array}\right] \text {, }
$$

$$
\text { and } \mathrm{x}=\left[\begin{array}{c}
c_{0} \\
c_{1} \\
\ddots \\
c_{n}
\end{array}\right] \text {. }
$$

Then $\mathbf{b}$ and $\mathbf{x}$ are the vectors dimension of $n$,

$$
h_{i}=x_{i+1}-x,
$$

$\alpha_{i}=\frac{3}{h_{i}}\left(a_{i+1}-a_{i}\right)-\frac{3}{h_{i-1}}\left(a_{i}-a_{i-1}\right)$ for $i=1,2, \ldots, n-1$. 
$a_{i}, b_{i}$ and $d_{i}$ can be calculate by the following these equations

$$
\begin{gathered}
a_{i}=y_{i} \text { where } i=0,1, \ldots, n, \\
b_{i}=\frac{\left(a_{i+1}-a_{i}\right)}{h_{i}}-\frac{h_{i}\left(c_{i+1}-2 c_{i}\right)}{3} \text { where } i=0,1, \ldots, n-1, \\
\text { And } d_{i}=\frac{\left(c_{i+1}-c_{i}\right)}{3 h_{i}} \text { where } i=0,1, \ldots, n-1 .
\end{gathered}
$$

The results of coefficients can always be written in the form of cubic function on $\left[x_{i}, x_{i+1}\right]$ where $i=0,1, \ldots, n-1$ as

$$
S_{i}(x)=a_{i}+b_{i}\left(x-x_{i}\right)+c_{i}\left(x-x_{i}\right)^{2}+d_{i}\left(x-x_{i}\right)^{3} .
$$

\section{Numerical Experiment}

This study is divided into two main steps. In the first step, hourly-based data collected at 8 monitoring stations along the Chao Phraya River during 05/3-10/2019 were interpolated with cubic spline to the initial condition $S(x, 0)(\mathrm{g} / \mathrm{l})$ and left boundary condition $S(0, t)(\mathrm{g} / \mathrm{l})$, adequately approximating the values at these conditions (see Figure 3 and 4). In the second step, salinity intrusion concentrations at all monitoring stations were numerically simulated and approximated by a simple advection-diffusion equation and MacCormack Scheme. Figure 5 and 6 show the approximated salinity concentrations in a red line together with scattered points of real data from two monitoring stations, one closest to the estuary and another one more distant to the estuary.

The optimum values of $u_{s}$ and $u_{w}$ of our model were found by assigning $6 u_{s}$ values and $6 u_{w}$ values (see Figure 7 to 10) to the model and determining the simulated salinity concentration for each combination of these $u_{s}$ and $u_{k}$ values. Then, the simulated concentration was compared to real salinity concentration to find the best match. It turned out that at $D=0.1, k=0.15, u_{w}=0.6$, $u_{s}=0.1$, the simulated concentrations best matched the real concentrations at two monitoring stations. We also used these optimum parameters to run our model at different times and compared the resulting simulated salinity concentrations to the real concentrations at $4,8,12$, 16, 20 and 24 (hrs.) at one monitoring station and found a good match between those values (See Table 1).

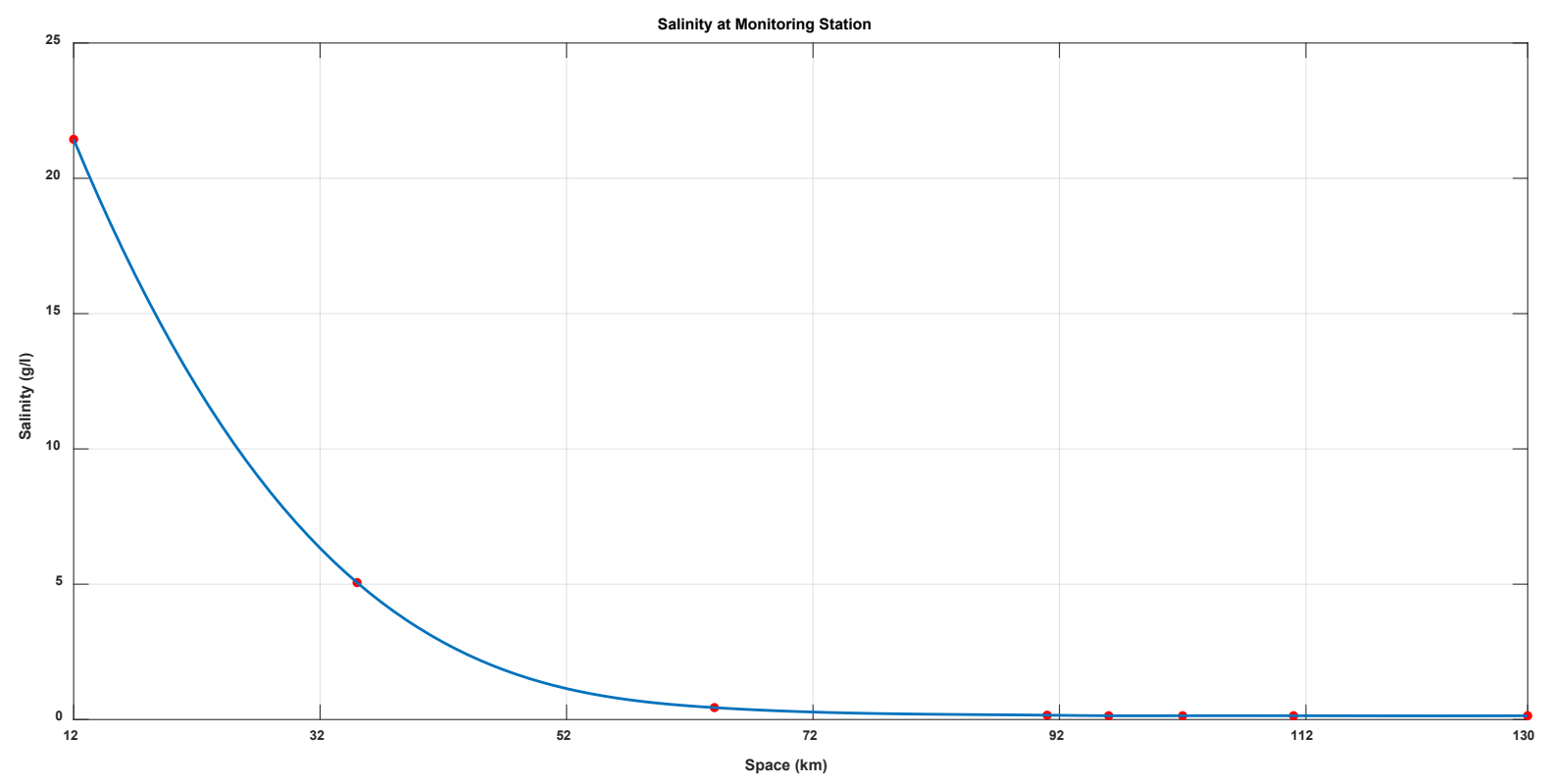

Figure 3. Cubic spline interpolated initial condition, $S(x, 0)(\mathrm{g} / \mathrm{l})$ 


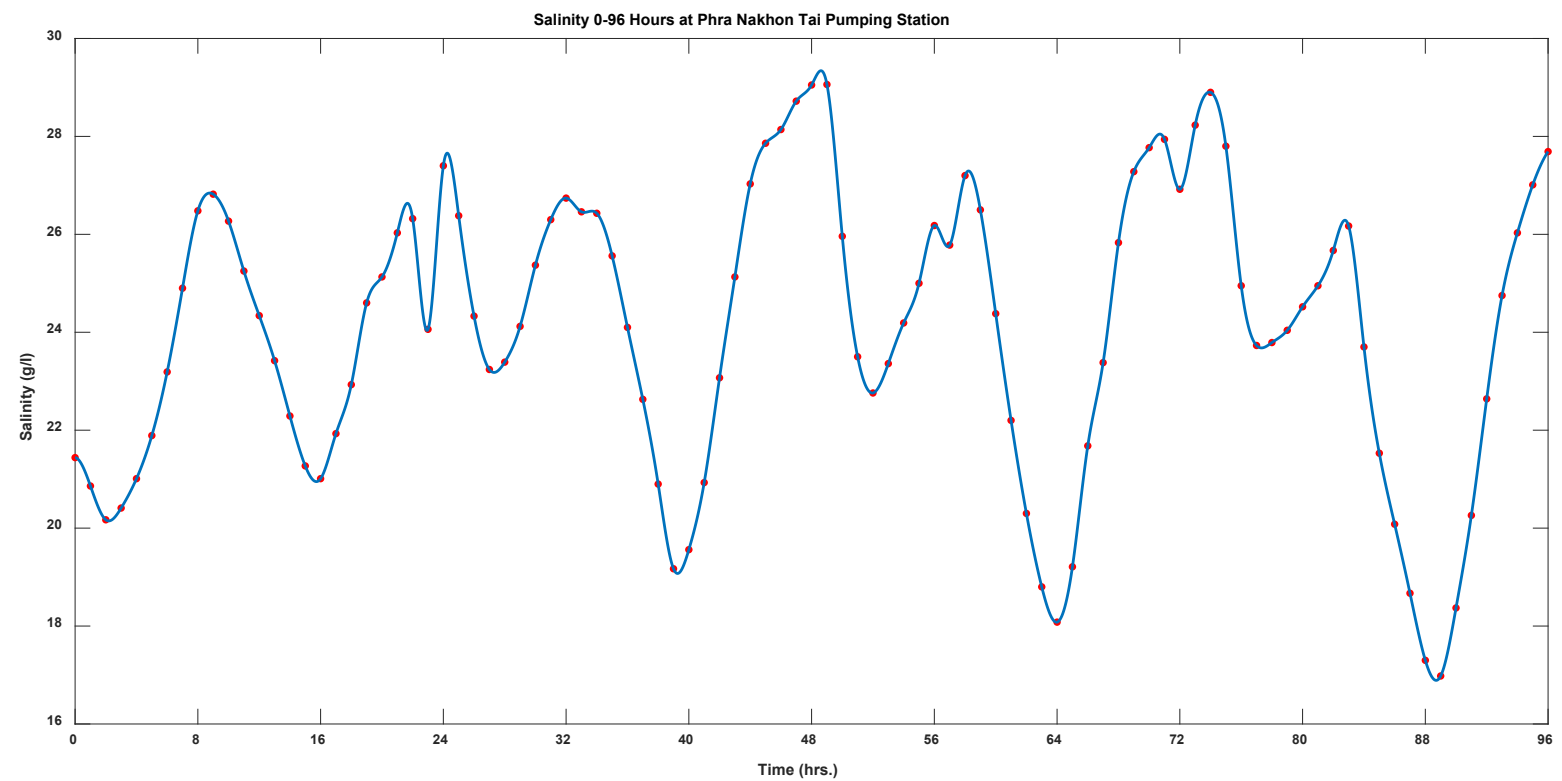

Figure 4. Cubic spline interpolated left boundary condition, $S(0, t)(\mathrm{g} / \mathrm{l})$

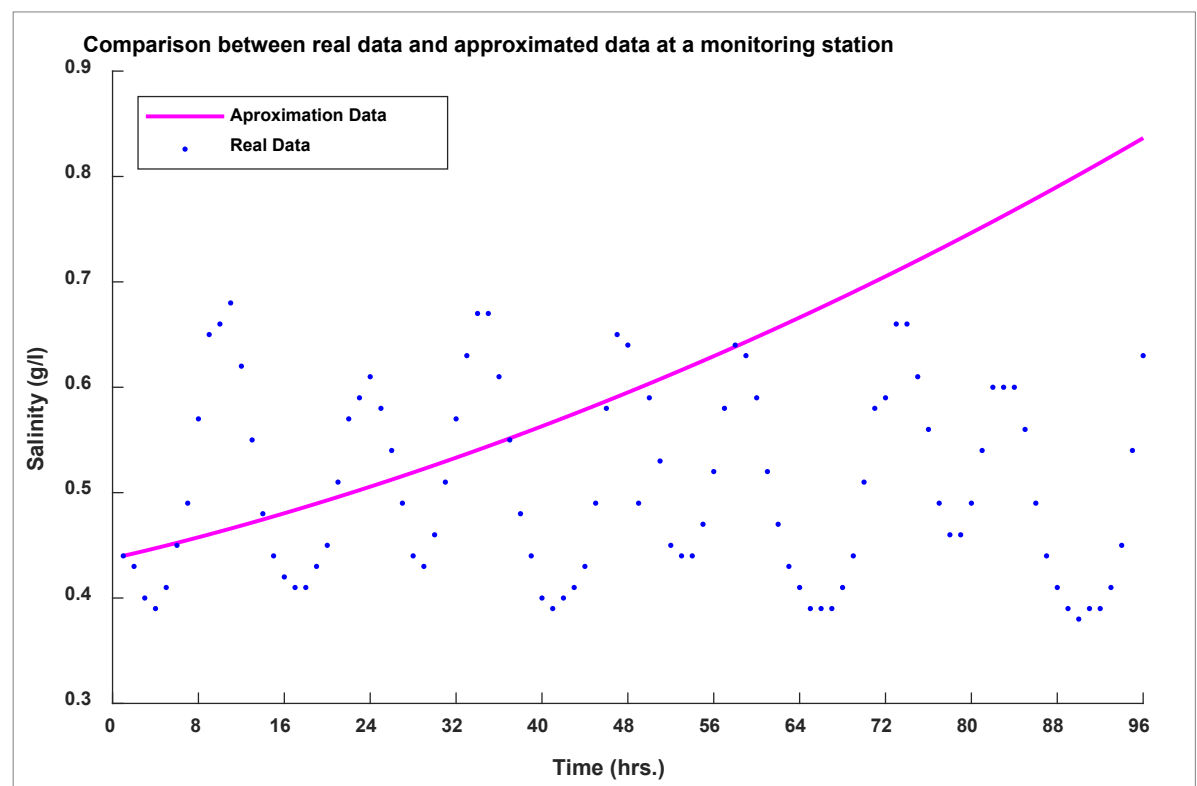

Figure 5. Comparison of salinity intrusion concentration (g/l) in 05/3-10/2019 between real data (blue -line) and approximated data (red-line) at a monitoring station, closest to the estuary 


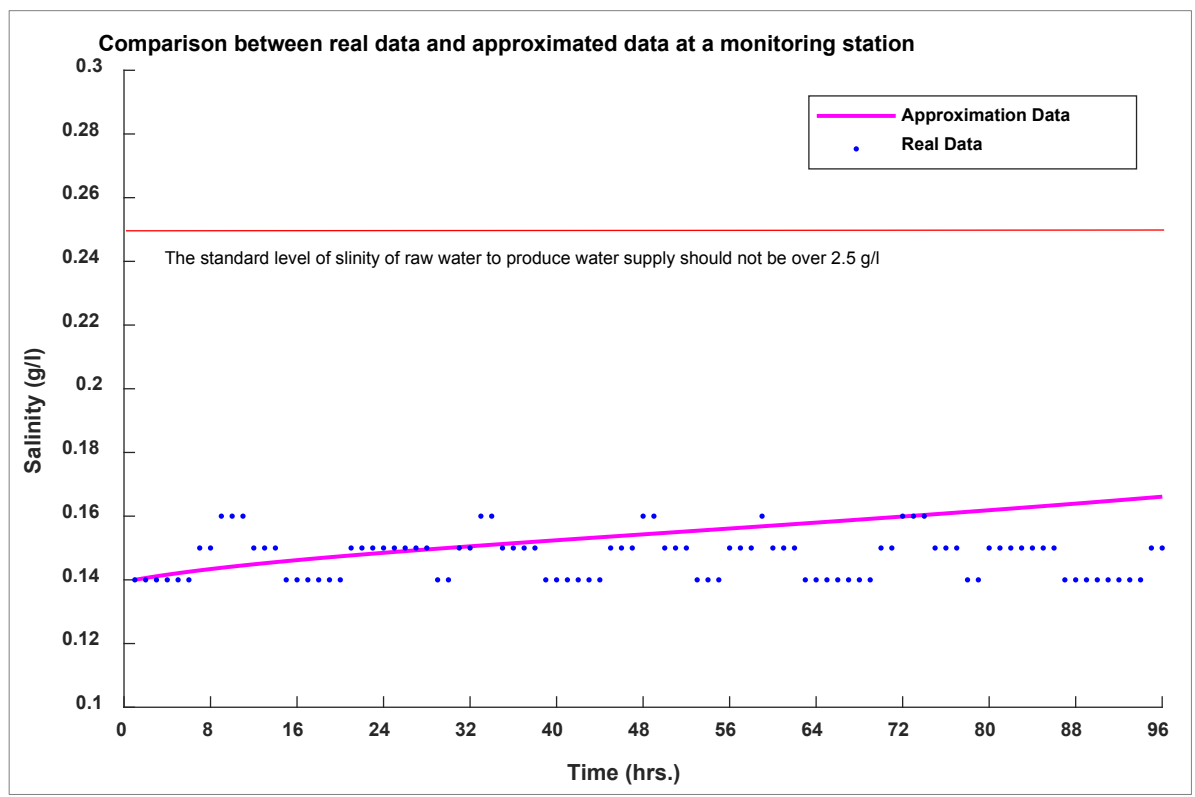

Figure 6. Comparison of salinity intrusion concentration (g/l) in 05/3-10/2019 between real data (blue-line) and approximated data (red-line) at another monitoring station, more distant to the estuary

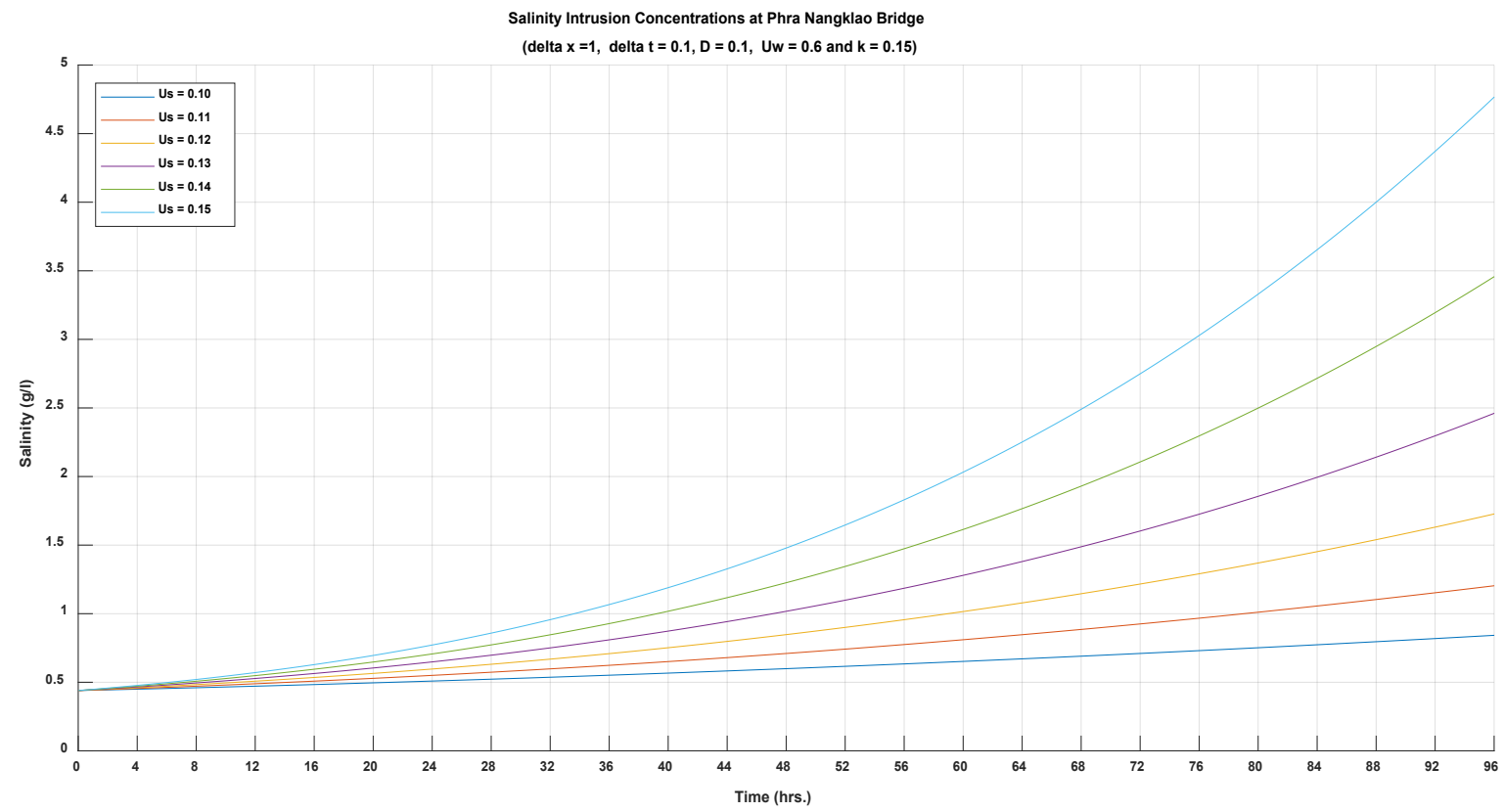

Figure 7. Comparison of salinity intrusion concentration curves for different $u_{s}$ at a monitoring station, distant to the estuary 
by a Developed Mathematical Model and MacCormack Scheme with Cubic Spline Interpolation

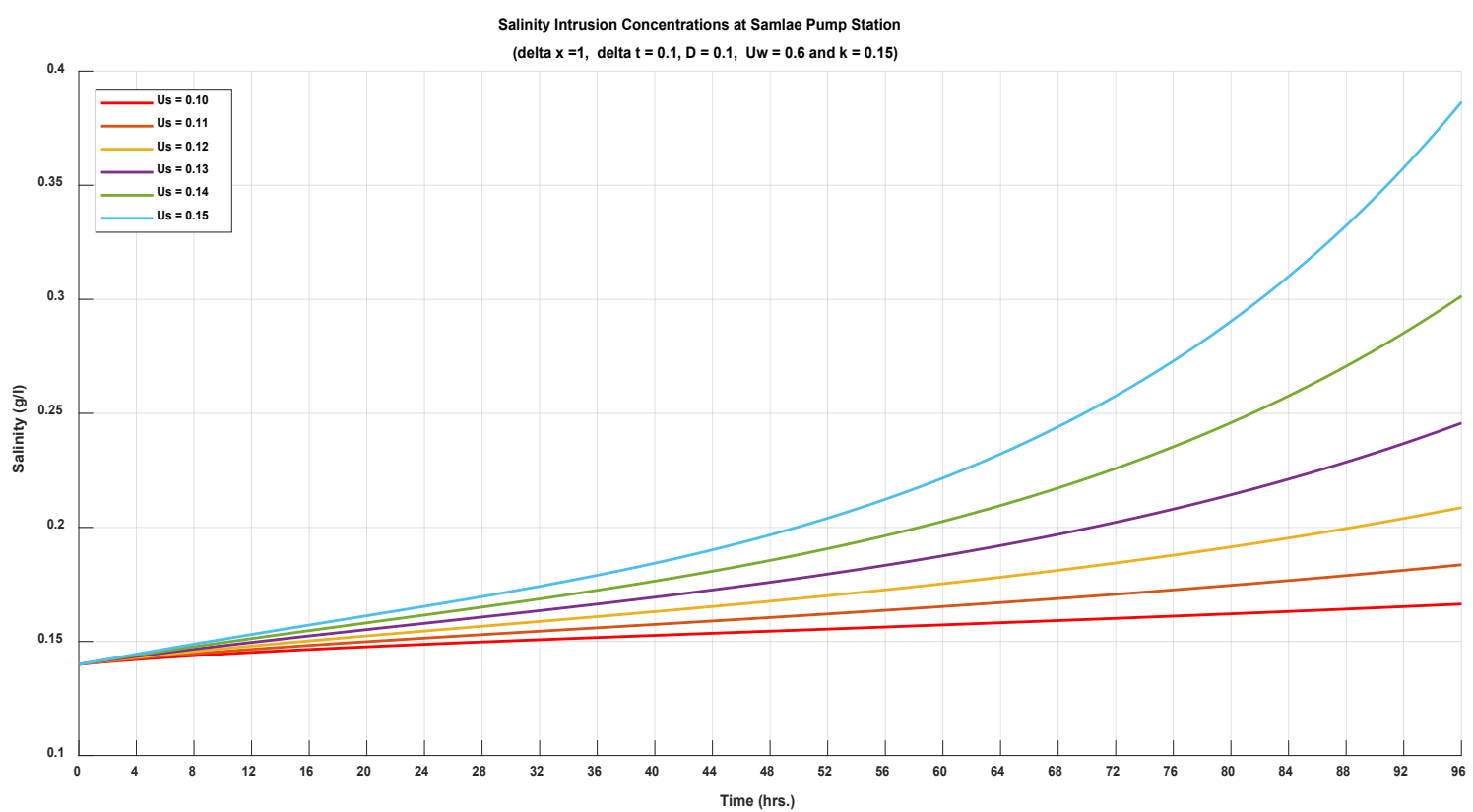

Figure 8. Comparison of salinity intrusion concentration curves for different $u_{s}$ at a monitoring station, more distant to the estuary

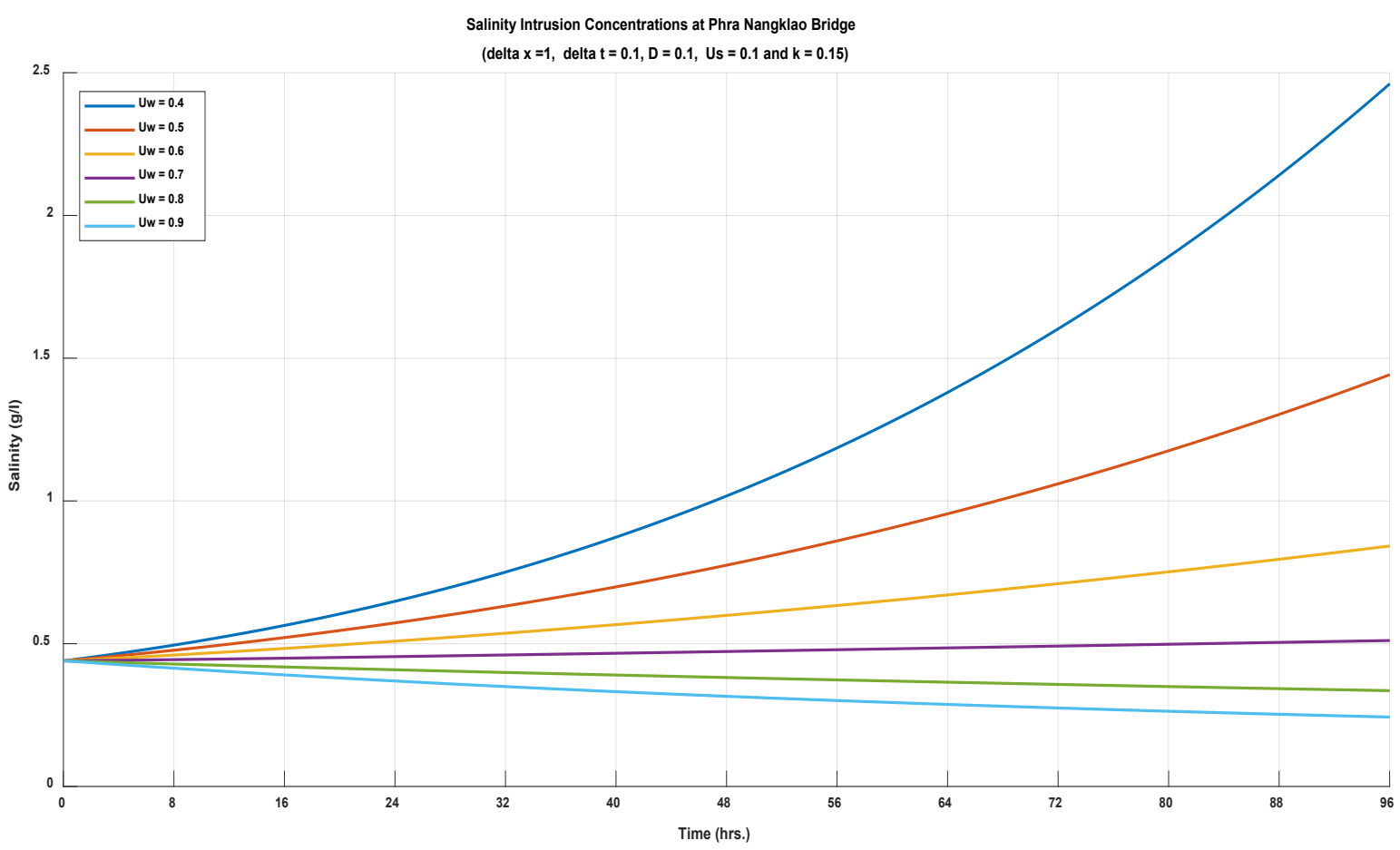

Figure 9. The comparison of the salinity intrusion concentration curves for different $u_{w}$ at a monitoring station, close to the estuary 


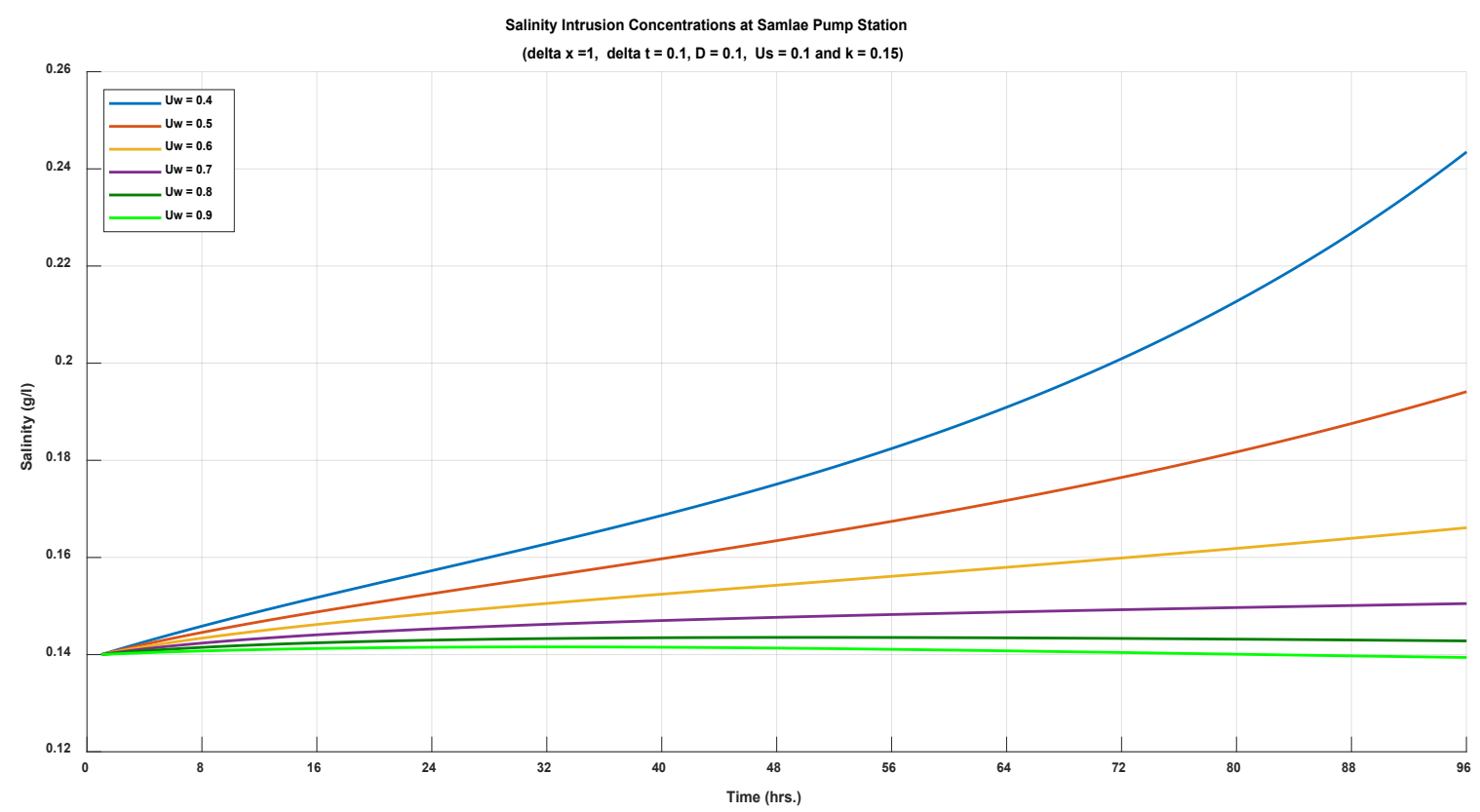

Figure 10. Comparison of salinity intrusion concentration curves for different $u_{w}$ at a monitoring station, more distant to the estuary

Table 1. Comparison of real salinity intrusion concentrations ( $\mathrm{g} / \mathrm{l})$ and approximated concentrations with $D=0.1, k=0.15, u_{w}=0.6, u_{s}=0.1$ at a monitoring station and 4, 8, 12, 16, 20 and $24 \mathrm{hr}$ collection times

\begin{tabular}{|c|c|c|c|c|c|c|}
\hline \multirow{2}{*}{$\begin{array}{c}\text { Date } \\
\text { 3-May-19 }\end{array}$} & \multicolumn{6}{|c|}{ Salinity Intrusion Concentration $S(x, t)$ (g/l) } \\
\hline & $4 \mathrm{hr}$ & $8 \mathrm{hr}$ & $12 \mathrm{hr}$ & $16 \mathrm{hr}$ & 20 hr & $24 \mathrm{hr}$ \\
\hline Real data & 0.14 & 0.16 & 0.15 & 0.14 & 0.15 & 0.15 \\
\hline Approximated data & 0.1421 & 0.1438 & 0.1452 & 0.1465 & 0.1477 & 0.1488 \\
\hline Error (\%) & 1.5019 & 10.1335 & 3.1820 & 4.6474 & 1.5509 & 0.8261 \\
\hline \multirow{2}{*}{$\begin{array}{c}\text { Date } \\
\text { 4-May-19 }\end{array}$} & \multicolumn{6}{|c|}{ Salinity Intrusion Concentration $S(x, t)(\mathbf{g} / \mathbf{l})$} \\
\hline & $4 \mathrm{hr}$ & 8 hr & $12 \mathrm{hr}$ & $16 \mathrm{hr}$ & 20 hr & $24 \mathrm{hr}$ \\
\hline Real data & 0.14 & 0.16 & 0.15 & 0.14 & 0.15 & 0.16 \\
\hline Approximated data & 0.1498 & 0.1508 & 0.1517 & 0.1527 & 0.1536 & 0.1545 \\
\hline Error (\%) & 6.9928 & 5.7643 & 1.1563 & 9.0511 & 2.3971 & 3.4291 \\
\hline \multirow{2}{*}{$\begin{array}{c}\text { Date } \\
\text { 5-May-19 }\end{array}$} & \multicolumn{6}{|c|}{ Salinity Intrusion Concentration $S(x, t)(\mathbf{g} / \mathbf{l})$} \\
\hline & $4 \mathrm{hr}$ & $8 \mathrm{hr}$ & $12 \mathrm{hr}$ & $16 \mathrm{hr}$ & $20 \mathrm{hr}$ & $24 \mathrm{hr}$ \\
\hline Real data & 0.14 & 0.15 & 0.15 & 0.14 & 0.14 & 0.16 \\
\hline Approximated data & 0.1554 & 0.1563 & 0.1573 & 0.1582 & 0.1592 & 0.1601 \\
\hline Error (\%) & 11.0213 & 4.2329 & 4.8506 & 13.0091 & 13.6879 & 0.0810 \\
\hline \multirow{2}{*}{$\begin{array}{c}\text { Date } \\
\text { 6-May-19 }\end{array}$} & \multicolumn{6}{|c|}{ Salinity Intrusion Concentration $S(x, t)(\mathbf{g} / \mathbf{l})$} \\
\hline & $4 \mathrm{hr}$ & $8 \mathrm{hr}$ & $12 \mathrm{hr}$ & $16 \mathrm{hr}$ & $20 \mathrm{hr}$ & $24 \mathrm{hr}$ \\
\hline Real data & 0.15 & 0.15 & 0.15 & 0.14 & 0.14 & 0.16 \\
\hline Approximated data & 0.1611 & 0.1621 & 0.1631 & 0.1642 & 0.1653 & 0.1664 \\
\hline Error (\%) & 7.4098 & 8.0805 & 8.7666 & 17.2888 & 18.0613 & 3.9978 \\
\hline
\end{tabular}




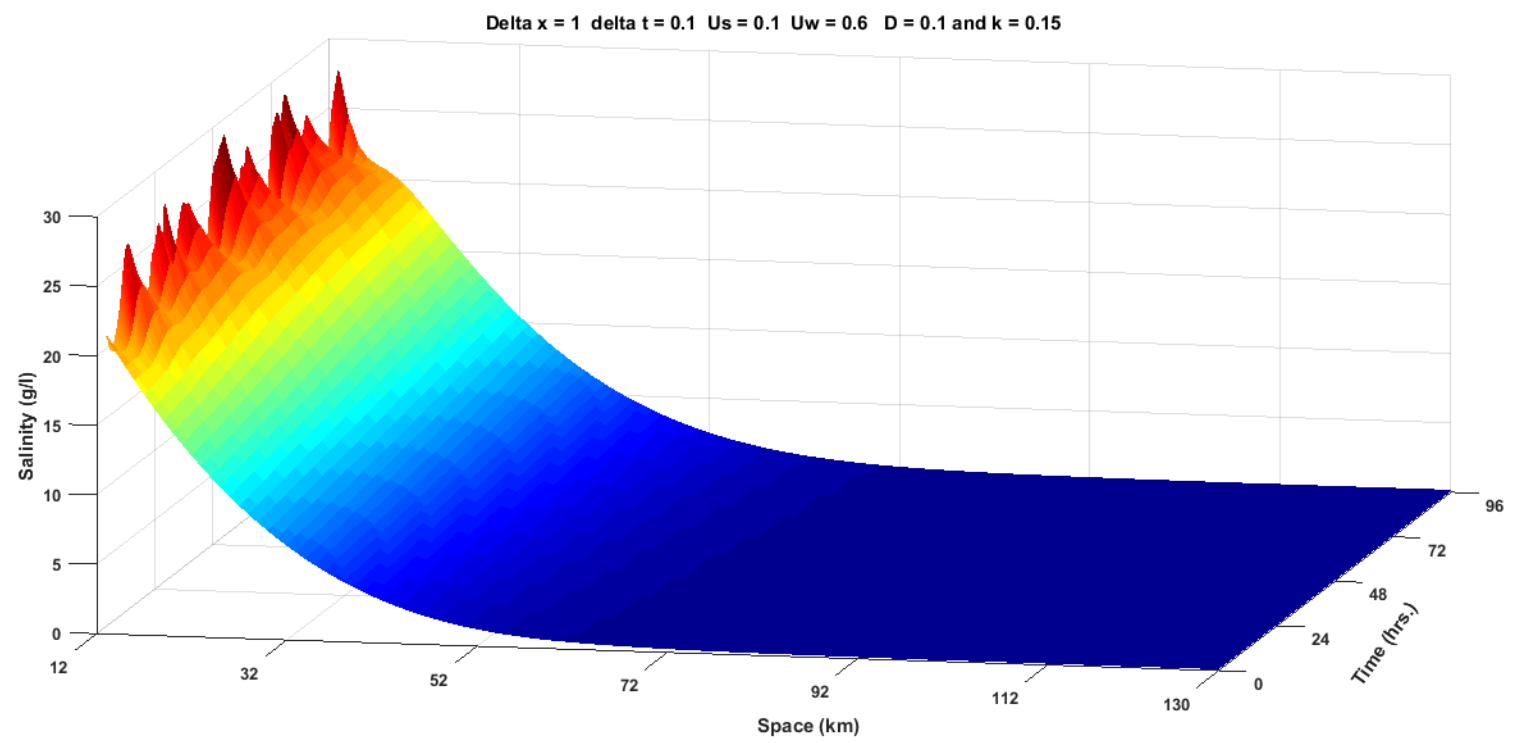

Figure 11. Approximated salinity intrusion concentrations $(g / 1)$ in $05 / 3-10 / 2019$ calculated by the MacCormack Scheme with cubic spline interpolated initial and boundary conditions

\section{Discussion and Conclusions}

In this study, salinity intrusion concentrations along the Chao Phraya River were approximated with a one-dimensional advection-diffusion equation and compared with real concentrations automatically monitored in real-time at several monitoring stations (from which data were affected by tides at the downstream). The values of the parameters $\left(u_{s}, u_{w}\right)$ of the equation were optimized. The resulting match between the approximated and real values was satisfactory. These optimum parameter values will be used in a future experiment that will test a new, improved model.

\section{Conflicts of Interest}

The authors declare that there are no conflicts of interest with any parties whatsoever.

\section{Acknowledgements}

This research was supported by the Center of Excellence in Mathematics, the Commission on Higher Education, Thailand. The authors greatly appreciate valuable comments from the referees from the metropolitan Waterworks Authority, Water Resources and Environment Department.

\section{REFERENCES}

[1] Department, Royal lrrigation. Summary of situation of salinity and Measures to reduce the impact. Bangkok: Bureau of Water Management and Hydrology, 2014.

[2] S. Wongsa. "Impact of Climate Change on Water Resources Management in the Lower Chao Phraty Basin,Thailand." Journal of Geoscience and Environment Protection, vol 3, pp. 53-58, 2015.

[3] Water Resources and Enviroment Department of Metropolitan Waterworks Authority, "Salinity Situation in the Chao Phraya River". 2018. Retrieved from http://rwc.mwa.co.th

[4] N. Pochai. "A numerical computation of a non-dimensional form of stream water quality model with hydrodynamic advection-dispersion-reaction equations." Nonlinear Analysis: Hybrid System, vol. 3, pp. 666-673, 2009.

[5] N. Pochai. "A numerical Treatment of Nondimensional Form of Water Quality Model in a Nonuniform Flow Stream Using Saulyev Scheme.” Mathematical Problems in Engineering, vol. 2011, pp. 1-15, 2011.

[6] K. Leewatchanakul. "Salinity intrusion in the Chao Pharya river." $\mathrm{PhD}$ thesis, Chulalongkirn University, 1988.

[7] P. Othata, and N. Pochai. "A one - dimensionl mathematical simulation to salinity control in a river with a barrage dam using an unconditionally stable explicit finite difference method." Advances in Difference Equations, vol. 2019, pp. 1-12, 2019.

[8] N. Seesod, and N. Pochai. "A numerical Computation to a Water-Quality Measurement in a Stream Using the Finite Volume Method." International Conference on Engineering, Applied Sciences,and Technology, vol. 2013, pp. $98-100,2013$.

[9] F. Mabood, and N. Pochai. "Asymptotic Solution for a water Quality Model in a Uniform Stream." International Journal of Engineering Mathematics, vol. 2013, pp. 1-4, 2013.

[10] N. Intaboot, and W. Taesombat. "Longitudinal Salinity 
Intrusion and Dispersion along the Thachin River Due to Sea Level Rise." Journal of Science and Technology, vol. 3, pp. 71-86, 2014.

[11] A. Owen, "Artificial diffusion in the numerical modelling of the advective transport of salinity." Applied Mathematical Modelling, vol. 8, pp. 116-120, 1984.

[12] K.Ralston, David, W. Rockwell Geyer, and J.A. Lerczak. "Subtidal Salinity and Velocity in the Hudson River Estuary: Observations and Modeling." American Meteorological Society, vol. 2008, pp. 753-770, 2008.

[13] R.M. Corless. "Compact finite differences and cubic splines.” May 19, 2018. Online: https://www.researchgate. net/publication/325282964_Compact_Finite_Differences_ and_Cubic_Splines.

[14] S. Ariffin, and A. Karim. "Cubic Spline Interpolation for Petroleum Engineering Data." Applied mathematical sciences, vol. 8, pp. 5083-5098, 2014.

[15] G. Li, and C.R. Jackson. "Simple, accurate, and efficient revisions to MacCormack and Saulyev schemes: High peclet numbers." Applied mathematics and computation, vol 186, pp. 610-622, 2007.

[16] R.R. Ahmad, N. Ghazali, A.S. Rambely, U.K.S. Din, and N. Hassan. "Application of Cubic Spline in the implementation of braces for the case of a child." Journal of mathematics and statistics, vol 8, pp. 144-149. 2012.

[17] N. Pochai. "Unconditional stable numericl techniques for a water-quality model in a non-uniform flow stream." Advances in Difference Equations, vol. 2017, pp. 1-13, 2017.

[18] M. Dehghan. "Weighted finite difference techniques for the one-dimensional advection-diffusion equation." Applied Mathematics and Computation, vol. 147, pp. 307-319, 2004.

[19] G. Shang, Z. Zaiyue, and C. Cungen. "Differentiation and numerical integral of the cubic spline interpolation." Journal of computers, vol. 6, pp. 2037-2044, 2011.

[20] L.B. Richard, and J.D. Faires. Numerical Analysis. 9th ed., Brooks/Cole, Cengage Learning, 2010. 